\title{
Septic cerebral stroke associated with infective endocarditis after the MitraClip procedure
}

\author{
Tomasz Zapolski*, Agnieszka Styczeń*, Mariusz Kozak, Marta Karaś-Głodek, \\ Wojciech Brzozowski, Andrzej Tomaszewski, Andrzej Wysokiński \\ Department of Cardiology, Medical University of Lublin, Lublin, Poland
}

Correspondence to:

Tomasz Zapolski, MD, PhD, Department of Cardiology, Medical University of Lublin, ul. Jaczewskiego 8, 20-954 Lublin, Poland, phone: +48817244255 , email: zapolia@wp.pl Received: May 16, 2020. Revision accepted: June 22, 2020. Published online: July 6, 2020. Kardiol Pol. 2020; 78 (9): 943-944 doi:10.33963/KP.15481 Copyright by the Author(s), 2020

* TZ and AS contributed equally to this work.
The MitraClip procedure, that is, the reduction of severe mitral regurgitation by the "edge-to-edge" method was introduced in 2003. The incidence of cerebral stroke connected with such a clinical situation is not high. ${ }^{1}$ This risk is caused by thrombus formation within the device, which is sometimes already encountered during the procedure. ${ }^{2}$ However, cerebral stroke related to vegetations in a patient with infective endocarditis (IE) on the MitraClip device has not yet been described.

A 77-year-old man was admitted to the Department of Neurology on February 10, 2020 due to acute brain stroke. The patient had had subfebrile temperature for several weeks before the admission, and a high septic fever $\left(40{ }^{\circ} \mathrm{C}\right)$ on the eve of stroke. In September 2019, the patient underwent the MitraClip procedure due to functional mitral regurgitation with 2 XTR MitraClips and 1 NTR MitraClip implantation. A single dose of $2 \mathrm{~g}$ of cefazolin was administered before the procedure. The MitraClip procedure lasted 3 hours and 25 minutes; the postoperative period was uneventful and was followed by a 24-hour stay in the intensive care unit. Laboratory tests performed on admission revealed the following: neutrophil count, $11.6 \times 10^{9} / 1$ (reference range, $\left.4-10 \times 10^{9} / 1\right)$; C-reactive protein, $107.4 \mathrm{mg} / \mathrm{l}$ (upper reference range, $5 \mathrm{mg} / \mathrm{l}$ ); troponin I, $701 \mathrm{ng} / \mathrm{l}$ (upper reference limit, $47 \mathrm{ng} / \mathrm{l}$ ), international normalized ratio, 3.6 (reference range, 0.8-1.2); D-dimer, $994 \mathrm{ng} / \mathrm{ml}$ (upper reference limit, $500 \mathrm{ng} / \mathrm{ml}$ ). Serial blood cultures, both initial and postantibiotic, were negative. Head computed tomography showed an irregular hypodense area with a diameter of $20 \mathrm{~mm}$ within the right cerebellar hemisphere with the features of an ischemic lesion.
Transthoracic echocardiography showed a vegetation $(0.8 \times 1 \mathrm{~cm})$ and a vegetation attached to the mitral valve and/or MitraClip arms (FIGURE $1 A$ and $1 \mathrm{~B}$ ). It was also confirmed by 2-dimensional transesophageal echocardiography (FIGURE $1 C$ and 1D) and three-dimensional transesophageal echocardiography (FIGURE $1 E$ and 1F). The primary reason for IE has not been established. On February 14, 2020, vancomycin therapy was introduced, which was continued until transferring the patient to the department of cardiac surgery, that is, until March 13, 2020. A biological prosthesis of the mitral valve was implanted (Hancock II No 31, Medtronic, Minneapolis, Minnesota, United States). In the culture obtained from the explanted valve, methicillin-resistant Staphylococcus epidermidis was detected (FIGURE 1).

MitraClip is a safe procedure in both perioperative and long-term follow-up; its effectiveness and safety increase with the number of procedures executed. ${ }^{3}$ Few cases of MitraClip and IE coexistence have been reported so far. ${ }^{4}$ Device-related vegetations can take the form of an infected thrombus, which may at times develop on the device surface early after implantation. ${ }^{2}$ However, in this case, it is implausible because the patient was adequately treated with anticoagulants due to permanent atrial fibrillation. The presence of vegetations was the only major criterion for endocarditis regarding serial negative blood cultures. It became the basis of IE diagnosis together with the detected 3 minor criteria (MitraClip presence, high fever, and cerebral arterial embolus). Despite its advantages, the operation is not a common procedure in such rare cases, and some patients are treated conservatively. ${ }^{5}$ 

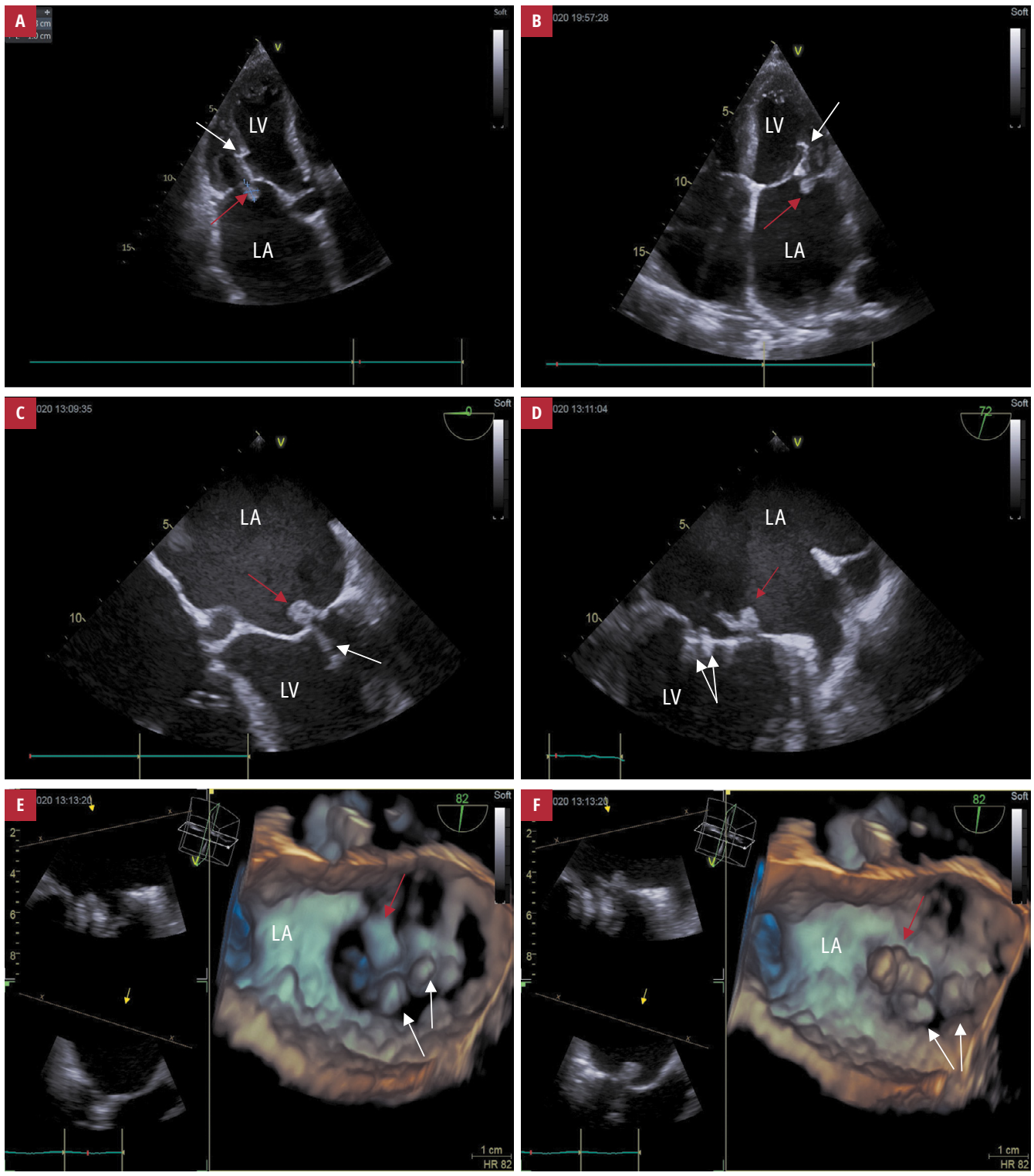

FIGURE 1 Transthoracic (TTE) and transesophageal echocardiography (TEE) with 2-dimensional imaging (2D) or 3-dimensional imaging (3D). All panels show 1 or 2 arms of the clip implanted into the mitral valve (white arrows) and vegetation attached to the mitral valve and / or clip (red arrows). A - 2D TTE, 2-chamber apical modified presentation; B - 2D TTE, 4-chamber apical presentation; C - 2D TEE, 4-chamber central transesophageal presentation; D - 2D TEE, 2-chamber central transesophageal presentation; E - 3D TEE central transesophageal presentation at the plane of the mitral annulus with much-reduced gains; F - 3D TEE central transesophageal presentation just above the plane of the mitral annulus

Abbreviations: $L A$, left atrium; LV, left ventricle

\section{CORRECTIONS}

This article was corrected on 0 ctober 27,2020 . The list of corrections is available at www.mp.pl/kardiologiapolska.

\section{ARTICLE INFORMATION}

CONFLICT OF INTEREST None declared.

OPEN ACCESS This is an Open Access article distributed under the terms of the Creative Commons Attribution-NonCommercial-NoDerivatives 4.0 International License (CC BY-NC-ND 4.0), allowing third parties to download articles and share them with others, provided the original work is properly cited, not changed in any way, distributed under the same license, and used for noncommercial purposes only. For commercial use, please contact the journal office at kardiologiapolska@ptkardio.pl.

HOW TO CITE Zapolski T, Styczeń A, Kozak M, et al. Septic cerebral stroke associated with infective endocarditis after the MitraClip procedure. Kardiol Pol. 2020; 78: 943-944. doi:10.33963/KP.15481

\section{REFERENCES}

1 Barros da Silva P, Sousa JP, Oliveiros B, et al. Stroke after transcatheter edge-to-edge mitral valve repair: a systematic review and meta-analysis. Euro Intervention. 2020; 15: 1401-1408.

2 Pręgowski J, Kłapyta A, Chmielak Z, et al. Incidence, clinical correlates, timing, and consequences of acute thrombus formation in patients undergoing the MitraClip procedure. Kardiol Pol. 2020; 78: 45-50.

3 Kłapyta A, Pręgowski J, Chmielak Z, et al. Role of the learning curve in very high-risk patients treated with MitraClip device for functional mitral regurgitation: a single-centre experience. Kardiol Pol. 2018; 76: 1564-1566.

4 Rempfer E, Basinger $\mathrm{H}$, Stawowy L, et al. MitraClip-associated endocarditis: Emergency department diagnosis with point of care ultrasound. J Emerg Med. 2020; 58: P942-946.

5 Boeder NF, Dörr 0, Rixe J, et al. Endocarditis after interventional repair of the mitral valve: review of a dilemma. Cardiovasc Revasc Med. 2017; 18: 141-144. 